\title{
educação

\section{Estratégias e incidência empresarial na atual política educacional brasileira: O caso do movimento 'Todos Pela Educação’}

\author{
Erika Moreira Martins ${ }^{I} \&$ Nora Rut KrawczyK ${ }^{I I}$ \\ Universidade de Campinas, Brasil
}

\begin{abstract}
Atualmente, observa-se na política educativa brasileira a influência constante de organizações empresariais que se entrelaçam com os quadros políticos, de entre as quais se destaca o Movimento Todos pela Educação (TPE). Procura-se aqui apresentar o TPE, discutindo seus objetivos e suas principais estratégias para incidir na política educativa brasileira. Utilizou-se vasta pesquisa documental e entrevistas com os principais atores do movimento. O TPE age como uma ampla coalizão, organizase em uma densa rede e atua como um Think Tank da educação. O presente artigo identifica indícios de um novo estágio de reestruturação do espaço público e de suas instituições. Em tal estágio, o empresariado busca o fortalecimento da capacidade de execução do aparelho estatal e institucional, tomando as rédeas desse processo, em nome da necessidade do controle social.
\end{abstract}

Palavras-chave: Reformas educativas; Educação e empresários; Políticas educativas; Advocacy; Brasil

\section{IN T RO D U Ç Ã O}

É possível afirmar que o Brasil se encontra num novo estágio de reconfiguração do espaço público, no qual o empresariado busca o fortalecimento da capacidade de execução do aparelho administrativo (governos e escolas) e, ao mesmo tempo, se posiciona no cenário político educacional como interlocutor privilegiado na condução das políticas educacionais. Tal comportamento se fundamenta na necessidade de controle social das políticas educacionais.

No Brasil, encontramos diversas organizações de origem empresarial que atuam na educação pública em parceria com os governos (como exemplo, citam-se as organizações: Parceiros da Educação, Instituto Ayrton Senna, Fundação Roberto Marinho, Fundação Lemann). De entre essas organizações, o Movimento 'Todos Pela Educação' (TPE) apresenta-se, atualmente, como um grupo de grande visibilidade, representando o projeto de um segmento dominante da sociedade que busca - com certo êxito, mas não sem resistências - construir uma hegemonia em torno da necessidade de profundas reformas na 
educação pública básica brasileira (Leher, 2010a; Martins, 2016).

Nas últimas décadas a educação básica no país $^{1}$ tem sofrido importantes mudanças, principalmente vinculadas à sua cobertura. Até à década de 1980, os índices de matrícula e êxito escolar em qualquer das etapas do ensino eram realmente constrangedores. A partir dos anos 1990, vêm se evidenciando políticas educacionais de expansão das diferentes etapas do ensino, tendendo em todos os casos à sua universalização - primeiro o ensino fundamental e atualmente a educação infantil e o ensino médio.

A expansão da matrícula e a inclusão de novos setores sociais está se produzindo ao mesmo tempo em que altos índices de abandono, fracasso escolar e distorção idade/série persistem. Assim, ninguém pode negar a necessidade de mudanças na educação brasileira para que esta dê conta dos novos contingentes de estudantes que estão acedendo às diferentes etapas do ensino e aos desafios que a realidade contemporânea apresenta. Isso produz uma forte preocupação entre diversos setores da sociedade, levando a que, particularmente no âmbito político, a educação se torne espaço de disputa de distintos - e até opostos - projetos. É uma disputa entre diferentes projetos sociais e educacionais de movimentos sociais e empresariais que geram tensões, conflitos e contradições nas políticas implementadas e na sua concretização no âmbito escolar. No entanto, como mostraremos mais adiante, o projeto empresarial tem conquistado importantes espaços, tornandose um interlocutor privilegiado dos órgãos governamentais (Krawczyk, 2014b).

É importante lembrar que o processo de industrialização no Brasil foi bastante tardio em relação à maioria dos países ocidentais, de forma que a educação demorou a transformar-se em prioridade para o desenvolvimento capitalista. Isso começou a mudar nas décadas de $1930 \mathrm{e}$ 1940, quando o presidente Getúlio Vargas adota uma política industrializante que reduz o poder econômico e político das oligarquias tradicionais, representante dos interesses agrário-comerciais. Esse processo leva ao rápido crescimento de uma burguesia industrial, principalmente em São Paulo, Minas Gerais e Rio Grande do Sul, que adquire influência nacional, tanto econômica quanto política (Cunha, 1991; Fernandes, 1981; Ribeiro, 1984). No campo da educação, é nesse período que se inicia a criação do chamado "Sistema S" - um conjunto composto por 11 instituições, cuja maioria tem sua sigla iniciada pela letra "S" - de formação profissional, para responder às novas demandas do mercado. Através desse sistema, cuja responsabilidade é compartilhada entre empresários e governo federal, o empresariado foi assumindo gradualmente a responsabilidade de formação de mão de obra qualificada, tornando essa rede de ensino cada vez mais significativa na formação dos trabalhadores (Franco, Pardal, Ventura, \& Dias, 2004).

Como podemos ver, a participação do empresariado na política educacional não é nova no Brasil. Ao contrário, a educação pública, desde sua gênese, desenvolveuse principalmente no bojo dos embates de diferentes projetos de sociedade das elites locais que, junto com a omissão do poder político, fez com que esse desenvolvimento se desse de forma descentralizada, desigual e, durante várias décadas, através da educação profissional.

A reforma do Estado imposta a partir da década de 1990 na maioria dos países latino-americanos muda a configuração de responsabilidades e

\footnotetext{
${ }^{1}$ A educação básica no Brasil abarca dos 4 aos 17 anos e está composta pela educação infantil (2 anos), ensino fundamental (9 anos) e ensino médio (3 anos).
} 
atribuições do Estado, do mercado e da sociedade, gerando uma nova lógica de governabilidade no âmbito da educação pública. É assim que, durante as gestões do presidente Fernando Henrique Cardoso (1995-1998/ 1999-2002), o executivo nacional e os organismos internacionais incentivam o empresariado a ter um maior envolvimento na responsabilidade pelo bemestar das pessoas, sobretudo pela sua educação. Emerge o slogan da "responsabilidade social" para designar o processo de descentralização de responsabilidades e atribuições para o mercado, do qual o Programa Comunidade Solidária funcionou como ponta de lança (Oliveira \& Haddad, 2001). Presidido pela primeira-dama Ruth Cardoso, nasceu com o propósito de otimizar as formas de gerenciamento de um conjunto de programas sociais, por meio da participação da sociedade civil (especialmente o empresariado) no combate à pobreza. Começam, assim, a surgir regulamentações e figuras jurídicas da sociedade civil na prestação de serviços públicos, que, através de parcerias complementam o orçamento público com recursos privados (Krawczyk, 2008, 2014b).

Hoje o movimento é diferente. Não é mais necessário estimular o empresariado a se envolver nas questões sociais, como fez a Comunidade Solidária. Existe uma presença constante de movimentos empresariais, em diferentes instâncias de decisão político-educativa, que, coletivamente e/ou individualmente, se entrelaçam com os quadros políticos, no Executivo nacional, estadual e municipal, como também no legislativo, estabelecendo formas explícitas e implícitas de cogestão. Naturalmente, a escola pública é um nicho de mercado ${ }^{2}$ importante, recriado e estimulado constantemente pelo setor privado, que atua em áreas como a produção e venda de material didático, a formação de professores, a prestação de consultorias, etc. No entanto, essa atuação não se resume apenas à realização de negócios com o governo, mas também (e cada vez mais) se centra em transmitir a ideologia empresarial nesse importante espaço de socialização das crianças e dos jovens (futuros trabalhadores). Ou seja, em inocular na escola pública a visão do mundo do empresariado.

Como analisaremos mais à frente, a pesquisa "Movimento 'Todos pela Educação': um projeto de nação para a educação brasileira" revelou a articulação entre governo e movimentos empresariais a partir da presença cada vez maior do TPE no espaço de definição de políticas públicas. Como procedimentos metodológicos, empreendeu-se a sistematização e análise de dados primários e secundários - tais como: documentos oficiais produzidos pelo TPE; entrevistas semiestruturadas; literatura científica relacionada ao tema (artigos e dissertações); notícias veiculadas em periódicos de grande circulação relacionadas ou produzidas pelo TPE -, além de observação realizada através da participação em eventos organizados pelo $\mathrm{TPE}^{3}$.

A sistematização e análise dos dados levou em consideração a necessidade de conhecer o TPE desde seu surgimento, abrangendo as motivações de seus principais organizadores, suas estratégias de ação para a produção de consensos, os

\footnotetext{
${ }^{2} \mathrm{O}$ conceito de 'nicho de mercado' é utilizado por David Harvey para indicar a necessidade do capitalismo de buscar novas formas e espaços de geração de lucro (Harvey, 2012).

${ }^{3}$ No ano de 2012 realizaram-se pessoalmente 7 entrevistas. De entre os entrevistados encontram-se: diretora executiva, integrante da Comissão técnica, membros e fundadores do Todos pela Educação. Também foi entrevistado o diretor executivo do grupo Mexicanos Primero (grupo mexicano membro da REDUCA e parceiro do Todos pela Educação). Analisaram-se também 14 documentos oficiais produzidos e divulgados pelo TPE no período entre 2006 e 2012. Complementarmente, inclui-se a análise de notícias em periódicos de circulação nacional e local, além de notícias divulgadas em portais eletrônicos. Foram utilizados 61 documentos divulgados entre 2006 e 2011.
} 
princípios e pressupostos que respaldam suas propostas, seu modo de assimilação e ressignificação de bandeiras históricas dos movimentos de educadores. Privilegiaram-se as relações e articulações entre os governos e o segmento empresarial representado pelo TPE, bem como a reorganização que a educação vem sofrendo a partir dessas relações. Tais alterações na política educacional vêm sendo legitimadas pelo princípio da corresponsabilidade pela educação.

\section{GÊNESE Do MOVIMENTO 'Todos PELA EduCaÇão'}

Lançado em 2006, o TPE surge por iniciativa de um grupo de empresários de diversos setores (incluindo os setores financeiro e industrial), que, no seu conjunto, representa uma importante fração da classe burguesa brasileira. Algumas das mais relevantes empresas que participam do TPE são o Grupo Itaú, o Gerdau, o Pão de Açúcar, Organizações Globo, além de institutos e fundações ligadas ao mundo empresarial, como o Instituto Ayrton Senna, o Grupo de Institutos, Fundações e Empresas (GIFE), a Fundação Roberto Marinho, o Instituto Ethos e o Grupo Abril (Martins, 2016, pp. 37-44).

O TPE se autodefine como uma aliança nacional apartidária (Todos Pela Educação, 2012). Representa uma ampla coalizão de defesa de causa ${ }^{4}$ formada pelos principais acionistas de empresas, diretores de organizações do terceiro setor e por líderes dos governos na área da educação. Financeiramente, o TPE conta com doações de importantes grupos empresariais e de organizações internacionais, como o Banco Interamericano de Desenvolvimento (BID). Sua plataforma de ação foi definida com base em uma pesquisa que visou conhecer as convergências entre as políticas educacionais e os programas de educação implementados por fundações e institutos de educação.

Vamos começar a trabalhar no que todo mundo está alinhado. A gente viu nessa matriz que tinha muito mais coisas convergentes do que divergentes e mesmo assim as pessoas não trabalhavam. A gente fez essa matriz também incluindo investidores privados, fundações, Fundação Itaú Social, Instituto Unibanco, Fundação Leman, Fundação Bradesco, Instituto Ayrton Senna. Pegamos os maiores investidores privados na educação e vimos que eles têm muita convergência, mas trabalham pouquíssimo juntos. Em 2005, havia pouquíssimo alinhamento do governo com esses institutos e com a sociedade civil de forma geral. Então, visualizamos um campo de atuação imediato: existiam espaço e necessidade de uma organização que articulasse esses diferentes esforços para um objetivo comum. Aí a gente começou a trabalhar (Entrevista com a diretora executiva do TPE, fevereiro de 2012, cit. in Martins, 2016, p. 40).

Logo depois, o TPE estabeleceu um conjunto de metas $^{5}$ mensuráveis, consensuais e de fácil compreensão; em seguida, organizou, divulgou dados sobre a educação pública, promoveu suas ideias nos principais meios de comunicação do país e incidiu sobre políticas educativas públicas junto aos governos e à sociedade.

Os argumentos e as propostas utilizados pelo

\footnotetext{
${ }^{4}$ Sabatier e Jenkins definem as coalizões advocatórias ou coalizões de defesa de causa como "a junção de atores públicos e privados, provenientes de diversas instituições e níveis governamentais, que dividem um conjunto de crenças e valores comuns e que buscam manipular as regras, orçamentos e recursos humanos governamentais visando atingir seus objetivos no longo prazo" (Simielli, 2008, p.117).

${ }^{5}$ São metas do TPE: 1) Toda a criança e jovem dos 4 aos 17 anos na escola; 2) Toda a criança plenamente alfabetizada até aos 8 anos; 3) Todo o aluno com aprendizado adequado à sua série; 4) Todo o jovem com o Ensino Médio concluído até aos 19 anos; 5) Investimento em Educação ampliado e bem gerido.
} 
TPE para a reorganização da educação pública coincidem com o senso-comum, alcançando, não sem resistência, aparente hegemonia junto à sociedade. Indique-se que o conceito de hegemonia que guia toda essa investigação é aqui entendido no sentido gramsciano, ou seja, como o exercício da capacidade de direção e liderança política e econômica. Hegemonia significa uma oposição à mera dominação, em que classes ou frações de classe simplesmente impõem seus projetos econômico-corporativos às demais frações sociais, sem considerar os projetos ou interesses destas últimas. Para Gramsci, a construção da hegemonia é atravessada por uma correlação de forças sociais, na qual uma combinação dessas forças tende a prevalecer $\mathrm{e}$ a ser difundida pela sociedade, determinando a direção econômica, política, intelectual e moral (Gramsci, 1980).

A emergência do TPE coincide com a importância estratégica que a educação adquire junto ao projeto de desenvolvimento do Brasil no início do século XXI, importância essa que foi compartilhada pelas frações de classes que passaram a ocupar o poder nacional a partir da ascensão de Luiz Inácio Lula da Silva à presidência ${ }^{6}$. Nesse momento, para se alcançar o patamar internacional de competitividade e desenvolvimento almejado, já não bastava a universalização da educação básica (Freitas, 2011, pp. 4-5). Esta deveria ser reorganizada através de uma forma de participação na qual governos e diversos setores da sociedade estivessem envolvidos - de diferentes formas - na corresponsabilidade pela qualidade da educação.
2. CORRESPONSABILIDADE PELA EDUCAÇÃO E REORGANIZAÇÃO DO SISTEMA EDUCATIVO BRASILEIRO

A incidência do TPE na educação pública é justificada por seus membros pelo valor da experiência empresarial que eles possuem e pela necessidade de que os diferentes setores da sociedade se tornem corresponsáveis pela educação no país.

A pedra angular da ética do Compromisso Todos Pela Educação é a CORRESPONSABILIDADE PELO TODO, que se consubstancia na atuação convergente, intercomplementar e sinérgica entre as políticas públicas, o mundo empresarial e as organizações sociais sem fins lucrativos; [...] $\mathrm{O}$ Estado tem o dever e a obrigação de ser o detentor dos fins universais (atender a todos). O mundo empresarial destaca-se pela sua capacidade de fazer acontecer (lógica dos meios) com eficiência, eficácia e efetividade. As Organizações Sociais Sem Fins Lucrativos (Terceiro Setor) caracterizam-se pela sua sensibilidade, criatividade e espírito de luta (Todos Pela Educação, 2006a, p. 7).

O TPE reconhece que houve avanços importantes no provimento da educação pública no país, mas questiona os governos porque não conseguiram conjugar o aumento da matrícula com a permanência dos alunos e a qualidade do ensino, tal como estariam demostrando os indicadores nacionais e internacionais (Todos Pela Educação, 2007a, p. 6). Para o TPE, a expressão mensurável da ineficiência do Estado e da má qualidade da educação revela-se nos índices de reprovação, abandono escolar, e, principalmente, no baixo desempenho dos estudantes em exames internacionais, como é

${ }^{6}$ Luiz Inácio Lula da Silva foi presidente do Brasil durante dois mandatos consecutivos: entre 2003 e 2006; e entre 2007 e 2010. 
o caso do PISA (Programme for International Student Assessment), sintetizados na expressão "a escola não ensina, a criança não aprende, e o Brasil não se desenvolve" (Todos Pela Educação, 2006b, p. 9).

A partir da análise das propostas do TPE, Martins (2016) aponta que esse movimento parte do diagnóstico de que a educação pública estaria atravessando uma forte crise que se manifesta em três dimensões: crise de qualidade, de responsabilidade e de gerenciamento. No enfrentamento das crises, o TPE propõe a reorganização da educação pública em torno de um projeto nacional, no qual a prioridade seria a qualidade da educação pública. A análise dos dados demonstra que para o TPE as crises de qualidade, responsabilidade e gerenciamento estão interligadas. A crise de qualidade seria resultado da incapacidade gerencial do Estado em administrar a educação pública e da falta de responsabilização da sociedade em pressionar/fiscalizar os governos. Por isso, um dos princípios do TPE é a corresponsabilidade pela educação. Assim, a responsabilidade pelos resultados educacionais pode ser compartilhada entre governos e sociedade, recuperando, simultaneamente, o papel do empresariado como sujeito privilegiado na interlocução com o poder executivo.

Para o movimento, a corresponsabilidade pela educação deve ocorrer, sem que isso signifique sobreposição aos interesses e à liderança de grupos empresariais. Uma das características dessa corresponsabilidade relaciona-se com a representatividade do TPE. Mesmo ambicionando mobilizar todos os segmentos da sociedade em torno de suas propostas, a interlocução com agentes fundamentais no processo educativo, além de precária, assume um caráter prescritivo. Os documentos analisados indicam que, para o TPE, a ideia de corresponsabilidade reserva aos professores e demais profissionais de educação um papel subalterno. Aquilo que o TPE apresenta como responsabilidade destes está delimitado ao simples cumprimento de recomendações, não obstante a declarada intenção do Movimento de mobilizar todos os segmentos da sociedade (Todos Pela Educação, 2007a, p. 13).

$\mathrm{Na}$ análise de documentos do TPE, a categoria docente é considerada a principal responsável pelas mudanças na educação. Sendo o professor responsável individualmente pelo desempenho dos alunos, a escola deve apoiá-lo "naquilo que ele sabe fazer: ensinar e garantir que os alunos aprendam [; assim] o professor tem o direito de se sentir responsável e de ser responsabilizado pelo desempenho de sua turma, e precisa ter oportunidades reais de aperfeiçoamento e acompanhamento profissional e de capacitação em serviço" (Todos Pela Educação, 2006b, pp. 26-27). O motivo do fracasso de reformas de movimentos educacionais anteriores teria sido a desconsideração e a não valorização dos professores, "gerando no magistério fortes resistências ideológicas e corporativas aos planos, programas, projetos e reformas vindos dos gabinetes do poder" (Todos Pela Educação, 2006b, pp. 25-26).

Cabe aos gestores "incentivar a inclusão e a permanência de todos os jovens na escola para que, por meio da qualificação educacional, as diferenças sociais sejam permanentemente superadas em nosso País" (Todos Pela Educação, 2010, p. 23). À Secretaria de Educação cabe articular um mecanismo eficiente de supervisão das escolas, com foco no resultado. O TPE sugere também que a gestão do plano de metas da Secretaria de Educação esteja amparada por um sistema de informação que colete dados das escolas em tempo real (Todos Pela Educação, 2006b, p. 30). Percebe-se que as orientações do TPE em relação ao que cabe à gestão e à Secretaria de Educação pautam-se pela gestão por resultados, incorporando uma racionalidade empresarial que tem na excelência e na eficácia 
os eixos do que seria uma educação de qualidade.

O papel da família também é questionado pelo Movimento. Os pais devem ser ativos, solidários e críticos dos educadores de seus filhos. Tomando como exemplo a exigência por qualidade que ocorre nas escolas privadas, na relação de corresponsabilidade pela educação, pais e alunos devem agir como consumidores:

Por ser a escola de seus filhos pública e gratuita, eles não acreditam que podem agir como os pais das escolas particulares, que reclamam e exigem seus direitos de consumidores [...]. Na escola pública, principalmente nas frequentadas pelos segmentos da população economicamente mais frágeis e vulneráveis, isto não ocorre porque essa exigência é vista como uma demonstração de ingratidão e de desrespeito para com as autoridades (Todos Pela Educação, 2006b, pp. 7-12).

As propostas do Movimento têm sofrido resistências por parte de alguns sindicatos de professores e de diferentes movimentos sociais que reivindicam uma participação democrática nas decisões a respeito da política educacional ${ }^{7}$ (Martins, 2016, pp. 105-106). Pesquisadores universitários associam grupos como o TPE aos Reformadores Empresariais (corporate reforms) estadunidenses (Freitas, 2012). Além disso, a forma de atuação do TPE também tem sido caracterizada como "neofilantropia empresarial" (Leher, 2010b), "nova filantropia” ou "filantrocapitalismo" (Ball \& Olmedo, 2012; Olmedo, 2013). De entre os questionamentos, podemos ressaltar a crítica ao enfoque empresarial na educação, o conceito de qualidade associado ao cumprimento das metas aferidas em testes padronizados e o modus operandi do TPE.
Vejamos as estratégias que o Movimento utiliza para interferir e, até mesmo, determinar políticas educacionais.

\section{EStRAtégias de AtUAÇão do MOVIMENTO 'TOdOS PELA EdUCAÇão’}

A necessidade de formar uma aliança na qual estivessem envolvidos grupos empresariais, governos e outros segmentos da sociedade no enfrentamento da má qualidade educativa advém da visão de alguns setores empresariais, segundo a qual a amplitude e a complexidade dos problemas sociais ultrapassariam as possibilidades do Estado ou de qualquer organização empresarial que se proponha a agir isoladamente. Sendo assim, esses empresários optaram por agir através de uma coalizão que passou a ter uma evidente intervenção em diferentes âmbitos governamentais como estratégia de controle da política educacional do país.

Tal como veremos a seguir, a interferência crescente e exitosa do TPE nas políticas educacionais nacionais e na formação da opinião de uma parte considerável da sociedade brasileira são resultado, também, de duas outras estratégias do movimento: a 'organização em rede' e os 'conhecimentos técnicos e comunicação'.

\subsection{REDE INTERORGANIZACIONAL - ENTRELAÇAMENTO ENTRE SUJEITOS E OR G A N I Z A Ç Õ ES}

Para garantir sua influência no Estado, os sócios fundadores do TPE atuam, simultaneamente, em vários espaços. Foi possível observar a constituição de uma rede informal composta por acionistas e diretores de empresas, membros

\footnotetext{
${ }^{7}$ Cf. "Carta aberta aos membros do Conselho de Governança do movimento Todos pela Educação", 2011. In http://www.une.org. br/2011/09/carta-aberta-ao-movimento-todos-pela-educacao/. Acesso em: 20/06/2017.
} 
de organizações do terceiro setor e da alta burocracia dos governos. A abordagem de rede, explica Fataar (2006, p. 643), é orientada por uma concepção específica do papel das estruturas e dos atores no processo político. Tal abordagem pressupõe o reconhecimento e a importância dos fenômenos estruturais e dos contextos para a compreensão da política, sem, entretanto, reduzi-los aos resultados das estruturas. Simultaneamente, as redes também são descritas como relações não hierárquicas $\mathrm{e}$ interdependentes que ligam uma variedade de atores sociais que compartilham interesses políticos comuns (Borzal, 1998; Lima, 2007). Embora as instituições impliquem estabilidade, as redes apontam para a fluidez e mudança da natureza da governança do Estado (Fataar, 2006).

$\mathrm{Na}$ rede formada pelo TPE, os fundadores assumem papéis ou articulam-se com entidades tradicionais da estrutura de representação de interesses de classe - Federação das Indústrias do Estado de São Paulo (FIESP), Federação Brasileira de Bancos (Febraban); com associações de natureza mercantil-filantrópica, ou seja, com fundações, institutos, ONGs; com organismos internacionais (como consultores); com o Estado, através de cargos executivos, representativos, ou como conselheiros (v. anexo). $\mathrm{Na}$ alta burocracia estatal, vários membros do TPE ocupam ou ocuparam importantes cargos: integrantes do Conselho Nacional de Educação ${ }^{8}$, da União Nacional dos Dirigentes Municipais de Educação ${ }^{9}$, presidentes do Instituto Nacional de Pesquisas Educacionais (INEP) ${ }^{10}$, assessores presidenciais $^{11}$ e mesmo o cargo de Ministro da Educação ${ }^{12}$.

É imperativo destacar que a participação simultânea em instituições de natureza tão diversa confere ao TPE capilaridade, legitimação e uma circulação e compartilhamento de suas ideias e valores, tais como: a defesa da filantropia, voluntariado, responsabilidade social empresarial, colaboração e corresponsabilidade, entre outros, tanto junto às instâncias decisórias no interior do aparelho do Estado, como no conjunto da sociedade, contribuindo, dessa forma, para a criação e consolidação de consensos.

A atuação do TPE não se limitou apenas à participação dos seus sócio-fundadores. O movimento empenhou-se para envolver um número cada vez maior de segmentos da sociedade em torno de suas propostas. A ampliação dos parceiros e a projeção midiática fizeram do TPE um movimento de dimensão nacional. Contudo, dentro de sua estrutura organizativa, os lugares de decisão (presidência, conselhos, coordenações) ainda são ocupados, predominantemente, por empresários, os quais demarcam as diretrizes e interesses fundamentais

\footnotetext{
${ }^{8}$ Integraram o Conselho Nacional de Educação os seguintes fundadores do TPE: Francisco Aparecido Cordão (conselheiro e expresidente), José Francisco Soares, Mozart Neves Ramos e Reynaldo Fernandes.

${ }^{9}$ Ex-integrantes da UNDIME e fundadoras do TPE: Cleuza Rodrigues Repulho (ex-presidente), Maria do Pilar Lacerda A. e Silva (ex-presidente) e Mariza Vasques de Abreu.

${ }^{10}$ Entre 2005 e 2009 a presidência do INEP foi ocupada por Reynaldo Fernandes, e, atualmente, este cargo é ocupado por José Francisco Soares. Ambos são fundadores do TPE.

${ }^{11}$ Diversos fundadores do TPE ocuparam posições de destaque na alta burocracia estatal: José Henrique Paim Fernandes, expresidente do Fundo Nacional de Desenvolvimento da Educação (FNDE) entre 2004 e 2006; Ricardo Henriques, ex-secretário executivo Ministério de Desenvolvimento Social em 2003 e membro da Secretaria de Ações Estratégicas/Presidência da República; Marcelo Côrtes Neri, ex-Presidente do Instituto de Pesquisa Econômica Aplicada (IPEA), Ricardo Kotscho, ex-secretário de Imprensa da Presidência da República (2003-2004) (Martins, 2016, p. 122).
}

${ }^{12}$ Fernando Haddad, ministro da educação entre 2005 e 2012, também é fundador do TPE. 
do movimento.

A partir da classificação proposta por Lima (2007), poderia se entender que o TPE se constitui como uma densa e descentralizada rede, com baixo grau de fragmentação, ou seja, cuja orientação ideológica, em seu conjunto, é coesa. Além disso, a rede de atores formada pelo TPE, em sua origem, foi auto-organizada, sendo composta por atores individuais. Fataar (2006) alerta que é importante entender que os atores ou, nesse caso, as redes não possuem identidades de sujeito estáveis, mas que desenvolvem sua subjetividade à luz do contexto estrutural em constante evolução em que sua atividade política está envolvida. Portanto, é na interferência nas políticas educacionais que a complexidade da rede formada pelo TPE e a interdependência entre atores e entidades se evidencia. Isso porque, na interlocução com o Estado, ora os membros do movimento - que participam de outras instâncias e compartilham dos mesmos ideais - agem isoladamente, ora agem como um ator coletivo, representando o próprio TPE. Assim, pode-se entender o TPE como uma rede de política nos moldes apresentados por Fataar (2006, p. 644), ou seja, como uma rede de relacionamento relativamente estável que mobiliza e agrupa recursos dispersos para que a ação coletiva possa ser orquestrada em prol de objetivo político comum. A rede formada pelo TPE promove interações formais e informais entre atores privados e públicos com interesses interdependentes que usam espaços políticos para promover seus interesses políticos. Como explica Borzal (1998), “a suposição básica é que a existência de redes de políticas, que refletem o status relativo e o poder de interesses particulares em uma área política, influenciam (embora não determinem) os resultados da política” (p. 258).

Tomemos como exemplo a discussão a respeito do projeto de "Lei de Responsabilidade Educacional" (Projeto de Lei No. 7.420/2006 e apensados) que, desde 2006, está tramitando na Câmara dos Deputados. Este projeto de lei foi proposto pela ex-deputada federal do Partido da Social Democracia Brasileira (PSDB) e sóciafundadora do TPE, Raquel Teixeira. Até ao ano de 2014, participaram das discussões em audiência pública 49 convidados na condição de secretários de educação, diretores de institutos de pesquisa, professores universitários, pesquisadores, etc. Destes, 21 também eram membros do movimento e compartilhavam das ideias do TPE. O próprio TPE, enquanto entidade coletiva, foi convidado para a discussão através da participação de sua diretora executiva (Martins, 2013).

Também encontramos a existência de parcerias entre entidades governamentais, privadas e o TPE, evidenciando o entrelaçamento entre seus membros e outros atores que influenciam na educação. É o caso, por exemplo, do acordo de cooperação ${ }^{13}$ firmado em 2014 entre o TPE, o INEP e a Associação Brasileira de Avaliação Educacional (ABAVE) para análise e divulgação dos resultados das avaliações externas da educação básica. Aqui, tanto o diretor do INEP, na época, como o da ABAVE são membros do TPE.

\subsection{Conhecimentos Técnicos e COMUNICAÇÃO}

O TPE possui uma projeção que nenhum outro grupo que atua junto da educação na sociedade brasileira possui: em pouco tempo esse movimento passou a ser considerado -

13 http://www.todospelaeducacao.org.br/reportagens-tpe/30074/abave-assina-termo-de-cooperacao-com-todos-pela-educacaoe-inep/?pag=ultima. Acesso em: 12/06/2017. 
sobretudo pela mídia - como um especialista em educação, obtendo, assim, uma posição de privilégio dentro do processo de política. Esse status foi alcançado também por meio da sua capacidade de mobilização e comunicação com a sociedade e da divulgação de conhecimentos técnicos - atuando como Think Tank da educação. Fataar (2006) explica que o conhecimento é intrínseco ao funcionamento dos governos $\mathrm{e}$ das redes políticas. Para esse autor, os governos contam com posições políticas cientificamente e tecnicamente informadas. Isso abre o espaço para coalizões de interesses políticos para influenciar o processo político: "A dependência do conhecimento tem implicações para a formulação de políticas, à medida que o poder se entrelaça com o conhecimento" (Fataar, 2006, p. 644).

O TPE operacionaliza essa estratégia de produção e divulgação de conhecimentos técnicos através de uma Comissão Técnica que produz e difunde documentos e vídeos, sistematiza experiências governamentais e de iniciativa privada consideradas bem sucedidas, monitora e divulga indicadores educacionais e resultados de avaliações estaduais e nacionais, sempre comparando a realidade nacional e internacional. A interlocução junto aos principais canais midiáticos do país foi viabilizada pela rede de contatos (empresários da mídia e profissionais da comunicação estão entre os membros do $\mathrm{TPE}^{14}$ ) e pelo poder econômico representados no TPE. Essas estratégias permitiram que o TPE se inserisse no debate político sobre educação e difundisse suas ideias em escolas, entidades, governos e sociedade em geral, reforçando seu status de "especialista em educação":
[...] tão ou mais importante do que os espaços ocupados, foi o fortalecimento do relacionamento com os jornalistas que cobrem a área da educação, nos grandes centros (São Paulo, Rio de Janeiro e Brasília) e em vários estados do país. Hoje, o Todos Pela Educação é procurado como fonte, para indicar fontes, na área da educação por diversos veículos de comunicação (Todos Pela Educação, 2007b).

Nesse ponto, a prioridade é dada à categoria dos formadores de opinião, através dos quais procuram atingir a sociedade como um todo. Em suas ações, o TPE oferece cursos de jornalismo em educação, colabora na preparação de entrevistas e sugere pautas indicando fontes a jornalistas e editores (Todos Pela Educação, 2007b). Também encontramos estratégias midiáticas de convencimento à comunidade, tais como artigos frequentes assinados pelos membros do TPE, a divulgação de dados estatísticos e de uma coletânea diária de notícias sobre educação. Esses e outros dados são disponibilizados em seu sítio eletrônico para o público no geral e também dão embasamento às suas propostas e à pressão que o TPE faz junto aos governos no cumprimento das metas educativas.

O objetivo principal dessa estratégia consiste em firmar consensos e estabelecer um discurso único em torno do tema educativo. A partir da legitimidade dada pela mídia, o TPE vem divulgando suas ideias, ganhando adesões e projetando nacionalmente suas propostas. Sendo produtor e difusor de conhecimento, e, portanto, de poder, o TPE estabelece relações de intercâmbio e interação com os setores mais tradicionais do poder estatal, como parlamentos, ministérios e burocracias.

Em relação às metas para a educação, também é importante destacar que existe

\footnotetext{
${ }^{14}$ Entre os fundadores do TPE encontram-se: José Roberto Marinho (vice-presidente Organizações Globo), Roberto Civita (Grupo Abril), Jaime Sirotsky e Nelson Sirotsky (presidente emérito e presidente, respectivamente, do Grupo RBS de Comunicação/TV Rede Brasil Sul). Ver: http://www.todospelaeducacao.org.br/quem-somos/quem-faz/. Acesso em 20/06/2017.
} 
um alinhamento entre as metas do TPE e as do governo, principalmente as que foram estabelecidas pelo Plano de Desenvolvimento da Educação (PDE). Não é de surpreender, uma vez que ambas as metas foram engendradas por pessoas que integram a comissão técnica do TPE e, simultaneamente, fazem ou fizeram parte de instâncias do governo executivo a partir do primeiro mandato presidencial de Luiz Inácio Lula da Silva.

O PDE foi lançado em 2007, durante o segundo mandato de Lula da Silva, no bojo de uma série de programas de desenvolvimento prioritários para o país. Para regulamentar seus objetivos e metas, o Ministério da Educação promulgou o decreto 6.094/2007: "Plano de Metas Compromisso Todos Pela Educação", que revela, através do próprio título, a articulação entre o PDE e o Movimento TPE.

O principal decreto assinado pelo presidente era o Programa de Metas Compromisso Todos Pela Educação, que reúne ações referentes à Educação Básica e foi assim chamado em reconhecimento à sintonia existente entre as 5 Metas defendidas pelo Movimento e os objetivos do Plano proposto pelo Ministério da Educação (MEC). Compartilhando o ideário defendido pelo Todos Pela Educação de que apenas com a busca incansável de resultados é possível melhorar a qualidade da Educação no Brasil, o MEC introduziu, entre outras medidas, de forma inédita, uma política de metas e indicadores de qualidade como condição para o repasse de recursos a estados e municípios. Também é programa de Nação, não apenas de um governo, cujo mandato é finito e requer, portanto, diálogo permanente com toda a sociedade, preservada sua rica diversidade de pontos de vista, e com esferas da administração pública (Todos Pela Educação, 2007b, s/p, grifos nossos).

Alguns pesquisadores têm apontado que a aliança com os setores dominantes permitiu que estes pudessem ter mais peso na definição da educação brasileira, incorporando (entre outras) a agenda empresarial representada pelo TPE no Plano de Desenvolvimento da Educação (PDE) (Leher, 2010a). De fato, na ascensão do Partido dos Trabalhadores (PT) ao poder federal, seu setor majoritário aproximou-se do empresariado, distanciando-se de suas bases originárias: “Talvez isso explique, de certo modo, por que o MEC, ao formular o PDE, o tenha feito em interlocução com a referida parcela da sociedade e não com os movimentos dos educadores" (Saviani, 2007, pp. 1242-1243). Como desdobramentos da implementação do PDE, as redes escolares sofreram uma invasão do vocabulário e das práticas gerencialistas: gestores, metas, eficiência, qualidade total, etc. (Leher, 2014), e os governos traduziram o aumento da qualidade da educação em alcance de metas e índices quantitativamente mensuráveis. Contudo, desde o seu lançamento, diversas outras propostas do Movimento foram incorporadas à política educacional brasileira: para além do caso emblemático do Plano de Desenvolvimento da Educação (PDE) e do "Plano de Metas Compromisso Todos Pela Educação" (Decreto No. 6.094/2007), destacam-se a criação da Avaliação Nacional da Alfabetização (ANA), a operacionalização do chamado Arranjo de Desenvolvimento da Educação (ADE) (Martins, 2016, pp. 77-111) e o trabalho de lobbying realizado junto à Câmara de Deputados para a reformulação do ensino médio (Todos Pela Educação, 2014, p. 44).

\subsection{A Constituição DE UMA REDE LATINOAMERICANA - REDUCA}

Como parte de uma estratégia maior de construção de um movimento para interferir na educação pública latinoamericana, o TPE, em parceria com o Banco Interamericano de Desenvolvimento (BID), promoveu o Encontro Latino-Americano de Organizações da Sociedade 
Civil pela Educação. De tal evento - ocorrido em 2011 na cidade de Brasília - participaram 13 organizações latino-americanas (cuja atuação se assemelha à do TPE), representantes do BID, o então Ministro da Educação, além de jornalistas, representantes de governos e do terceiro setor. Nesse encontro foi criada a REDUCA - Rede Latinoamericana de Organizações da Sociedade Civil pela Educação (Martins, 2016, p. 90).

Atualmente, formam parte da REDUCA catorze organizações. São elas: Proyecto EducAR 2050 (Argentina); Todos pela Educação (Brasil); Empresarios por la Educación (Colômbia); Fundación Educación 2020 (Chile); Fepade (El Salvador); Grupo FARO (Equador); Empresarios por la Educación (Guatemala); Ferema (Honduras); Mexicanos Primero (México); Eduquemos (Nicarágua); Unidos por la Educación (Panamá); Juntos por la Educación (Paraguai); Empresarios por la Educación (Peru); e EDUCA (República Dominicana). Desde seu lançamento, a REDUCA tem se fortalecido na América Latina através da atuação na educação pública dos países nos quais está presente. Anualmente, a REDUCA realiza reuniões das quais participam seus membros, além de organizações internacionais, como o BID, acadêmicos e políticos. Em 2013, a Rede passou a receber financiamento da União Europeia (UE) para execução de projetos nas áreas de 'evasão e reprovação escolar', 'carreira docente e formação de gestores' e 'educação infantil', a serem implementados na América Latina (União Europeia, 2013).

De entre as organizações que compõem a REDUCA, o TPE é compreendido pelo BID e também pelos demais grupos que integram a rede como o caso mais exitoso e o exemplo a ser seguido, devido, justamente, ao apoio que recebe da grande mídia brasileira e também à sua capacidade de organização, penetração e atuação junto ao governo e à sociedade, de modo geral. Tal êxito só pode ser compreendido se analisarmos o TPE como uma nova força que, ao inserir-se na arena de disputas políticas que conformam o atual cenário brasileiro, conjuga as demandas e propostas para a educação provenientes do governo, da iniciativa privada e de outros setores da sociedade ${ }^{15}$.

\section{CONSIDERAÇÕES FINAIS}

Como foi possível perceber pela análise do Movimento Todos pela Educação, a produção político-educacional não passou apenas a ser um patrimônio mercadológico, mas também está se tornando um patrimônio ideológico de um setor da burguesia brasileira. Tal patrimônio ideológico se concretiza reconfigurando os espaços públicos do país e gerando novos mecanismos de controle social para além das instâncias formais de participação. A atitude proativa desse setor está presente em diferentes espaços de ação social (encontros, mídia, publicações, serviços para a comunidade educativa) e esferas de governo (executivos, federal, estadual, legislativo, municípios). E, sobretudo, conta com o apoio do aparato de Estado, que compartilha suas propostas e procura implementá-las.

É um processo gestado durante décadas e que, no caso da educação, se viu incentivado por uma conjuntura nacional e internacional com as seguintes características: uma pseudodemocratização da educação; o aumento da cobertura e o ingresso de novos setores sociais que têm tornado a escola pública também mais requisitada ideologicamente pelos diferentes setores sociais; a exaltação da eficiência e da universalidade dos modelos de gestão privada (conhecidos como "tecnologia empresarial"); e o encorajamento (por parte de organizações

\footnotetext{
${ }^{15}$ Atualmente estamos conduzindo uma investigação, financiada pela FAPESP, a respeito da Rede Latinoamericana de Organizações da Sociedade Civil para Educação - REDUCA.
} 
internacionais $^{16}$ e governamentais) do setor empresarial para intervir na política educacional. A tudo isso se soma o peso que os indicadores educacionais adquiriram nos últimos anos. Eles hoje são considerados não só na avaliação do desenvolvimento humano (IDH) dos países, mas também na classificação de risco para fins de investimentos internacionais.

O discurso alarmante sobre a situação da educação brasileira proferido pelo TPE, também presente com bastante frequência nos diferentes meios de comunicação, justifica a busca de soluções rápidas e até mágicas que, além do mais, sejam compatíveis com os tempos políticos nacionais e internacionais. Quando o TPE se refere à crise da educação brasileira, está pondo ênfase na necessidade de reorganizar a educação pública a partir de práticas gerenciais referendadas por organismos internacionais, sob o imperativo do Consenso de Washington (1989). Tratou-se, então, de definir receitas para a reforma dos estados latino-americanos como requisito para a concessão de novos empréstimos e cooperação econômica.

Nas últimas décadas, no marco das reformas educacionais, buscou-se principalmente a reconfiguração da gestão pública, através de mudanças das competências e responsabilidades do Estado, do mercado e da instituição escolar. Para tanto, as palavras de ordem na definição de políticas passaram a ser as evidências e o pragmatismo (conhecimento produzido em curto prazo e orientado pelas demandas). Ao mesmo tempo, a economia tornou-se a disciplina invocada para análise da eficiência das políticas educacionais (Delvaux, 2009; Krawczyk, 2014a). Tal lógica estimula institutos, ONGs, empresas de consultoria e fundações empresariais a buscar evidências empíricas nacionais e internacionais, gerando, como define o TPE, "conhecimentos técnicos" úteis para a definição de políticas educacionais.

As referências empíricas utilizadas pelas organizações empresariais são oriundas de diferentes países, principalmente das políticas educacionais que os Estados Unidos têm implementado no marco de uma renovação da racionalidade organizacional da educação pública, a partir da divulgação, em 1981, do relatório da National Commission for Excellence in Education, intitulado "Uma nação em perigo". A partir de então, foi inaugurada a era dos testes como instrumento de controle das unidades escolares; da responsabilização dos docentes por esse desempenho e da implantação do sistema de remuneração variável; e de novas formas de gestão das escolas públicas envolvendo as famílias e o setor privado (Klees, 2012). Também formaram parte dessa reforma a implantação de padrões curriculares comuns (common core) e de um conjunto de valores para incentivar o empreendedorismo nas crianças e jovens. Vários empresários e suas organizações apoiamse na divulgação de experiências, pesquisas e publicações que procuram oferecer evidências da eficiência do caminho escolhido pela política estadunidense. Essas e outras informações compõem um pacote de evidências empíricas e conhecimento técnico que circulam em fóruns nacionais e internacionais, legitimando as recomendações.

O setor da sociedade que hoje detém a hegemonia na arena político-educacional pode ser reconhecido como pertencente à 'burguesia interna', aquela que, segundo Boito Jr. (2012), “ocupa uma posição intermediária entre a antiga burguesia nacional, passível de adotar práticas anti-imperialistas, e a velha burguesia compradora, mera extensão do imperialismo

\footnotetext{
${ }^{16}$ É o caso do PREAL (Programa de Reforma Educativa para América Latina) que, através de suas publicações e encontros, promove a articulação entre o empresariado e os executores de políticas públicas em diferentes países da região (Krawczyk \& Grinkraut, 2014).
} 
no interior desses países" (p. 67) ${ }^{17}$. Muito heterogênea, englobando segmentos que vão desde grandes grupos industriais ao sistema financeiro, passando pelas cadeias de varejo e outras áreas de negócio, a burguesia interna é, por si só, contraditória em seus interesses. O que unifica setores tão diferentes é o seu compromisso com o capital financeiro internacional, mas também com uma indústria nacional preparada para a concorrência externa. Um dos principais elementos que a caracteriza é sua relação com o estado brasileiro, que, segundo Boito Jr. (2012), a protege e participa de seus projetos. Pode-se dizer, também, que, pelo menos no campo educacional, esse setor da burguesia tem um projeto para o país. A competitividade do país no mercado globalizado é a chave desse projeto almejado, e o lugar do Brasil no ranking internacional da qualidade de seus recursos humanos apresentase como uma das variáveis imprescindíveis para atingir esse objetivo. A qualidade da educação brasileira é convalidada por mecanismos de regulação internacionais, tais como o PISA, que ao mesmo tempo direcionam o trabalho escolar.

As tensões, disputas e conflitos no governo são intrínsecos à relação democracia-capitalismo, pois expressam o questionamento à reprodução das estruturas de poder. Compreender a educação como espaço de construção de hegemonia nos permitiu avançar na análise de suas contradições e do complexo e controvertido processo de definição de políticas. Mas é possível afirmar que cada estágio do capitalismo comporta uma particular dinâmica de construção de hegemonia burguesa. Precisamos aprofundar a compreensão dessa dinâmica, do seu universo de contradições e das formas de construção contra-hegemônica.

\section{FINANCIAMENTO}

$\mathrm{O}$ artigo é produto de pesquisa desenvolvida com o apoio da Fundação de Amparo à Pesquisa do Estado de São Paulo - FAPESP.

\section{REFERÊ NCIAS}

Ball, S. J., \& Olmedo, A. (2012). Global social capitalism: Using enterprise to solve the problems of the world. Citizenship, Social and Economics Education, 10(2-3), 83-90.

Boito Jr., A. (2012). Governos Lula: A nova burguesia nacional no poder. In A. Boito Jr. \& A. Galvão (Orgs.), Política e classes sociais no Brasil dos anos 2000 (pp. 67-104). São Paulo: Alameda.

Borzal, T. A. (1998). Organizing Babylon: On the different conceptions of policy networks. Public Administration, 76, 253-273.

Cunha, L. A. (1991). Educação, Estado e democracia no Brasil. São Paulo: Cortez.

Delvaux, B. (2009). Qual é o papel do conhecimento na ação política? Educação \& Sociedade, 30(109), 959-985.

Fataar, A. (2006). Policy networks in recalibrated political terrain: The case of school curriculum policy and politics in South Africa. Journal of Education Policy, 21(6), 641-659.

Fernandes, F. (1981). A revolução burguesa no Brasil: Ensaio de interpretação sociológica. Rio de Janeiro: Zahar.

Franco, M. L. B., Pardal, L., Ventura, A., \& Dias, C. (2004). Ensino médio e ensino técnico no Brasil e em Portugal: Raízes históricas e panorama atual. Campinas: Autores Associados.

Freitas, L. C. (2011, março). Responsabilização, meritocracia e privatização: Conseguiremos escapar ao neotecnicismo? Comunicação apresentada no Seminário de Educação Brasileira, Campinas, Brasil.

Freitas, L. C. (2012). Os reformadores empresariais da educação: Da desmoralização

\footnotetext{
${ }^{17}$ Armando Boito Jr. retoma o conceito de burguesia interna, cunhado por Poulantzas na década de 1970, que, segundo o autor, não se encontrava em vias de desaparecimento com a nova onda de internacionalização da economia capitalista.
} 
do magistério à destruição do sistema público de educação. Educação \& Sociedade, 33(19), 379-404.

Gramsci, A. (1980). Análisis de las situaciones, relaciones de fuerzas. Nueva Antropología, 4, 15-16.

Harvey, D. (2012). Condição pós-moderna. São Paulo: Loyola.

Klees, S. J., Samoff, J., \& Stromquist, N. P. (Eds.) (2012). The World Bank and education. Critiques and alternatives. Roterdam/Boston/ Taipei: Sense Publishers.

Krawczyk, N. (2008). Em busca de uma nova governabilidade na educação. In D. Andrade \& M. F. F. Rosar (Orgs.), Política e gestão da educação (pp. 59-72). Belo Horizonte: Autêntica.

Krawczyk, N. (2014a). Sociologia do Ensino Médio. Crítica ao economicismo na política educacional. São Paulo: Cortez.

Krawczyk, N. (2014b). Ensino médio: Empresários dão as cartas na escola pública. Educação \& Sociedade, 35(126), 21-41.

Krawczyk, N., \& Grinkraut, A. (2014). Ensino médio: Um campo de disputa. Research Study Report, CNPq. Diagnóstico e propostas dos organismos internacionais 2000-2013. Mimeo.

Leher, R. (2010a). Educação no governo de Lula da Silva: A ruptura que não aconteceu. In J. P. A. Magalhães et al. (Orgs.), Os anos Lula. Contribuições para um balanço crítico 20032010 (pp. 369-412). Rio de Janeiro: Garamond.

Leher, R. (2010b). Neoliberalismo se apropria da ideia de "inclusão" para privatizar a educação e a política educacional do Banco Mundial para a periferia do capitalismo. Jornal dos Sem Terra, 308 (s/p).

Leher, R. (2014). Estratégia política e Plano Nacional de Educação. Revista Eletrônica Marxismo 21. Dossiê Temático Marxismo e Educação. Disponível em: https://marxismo21. org/wp-content/uploads/2014/08/R-LeherEstrat\%C3\%A9gia-Pol\%C3\%ADtica-e-PlanoNacional-Educa\%C3\%A7\%C3\%A3o.pdf. Acesso em: 30/04/2018.
Lima, J. (2007). Redes na educação: Questões políticas e conceituais. Revista Portuguesa de Educação, 20(2), 151-181.

Martins, E. M. (2013). Responsabilidade educacional e atuação do Todos pela Educação. In L. C. Almeida, I. R. Pino, J. M. R. Pinto, \& A. B. Gouveia (Orgs.), IV Seminário de Educação Brasileira: PNE em foco (vol. 1, s/p). Campinas, SP: CEDES.

Martins, E. M. (2016). Todos pela Educação? Como os empresários estão determinando a política educacional brasileira. Rio de Janeiro: Lamparina.

Oliveira, A. C., \& Haddad, S. (2001). As organizações da sociedade civil e as ONGs de educação. Cadernos de Pesquisa, 112, 61-83.

Olmedo, A. (2013). From England with love... ARK, heterarchies and global 'philanthropic governance'. Journal of Education Policy, 29(5), 575-597.

Ribeiro, M. L. (1984). História da educação brasileira. A organização escolar. São Paulo: Editora Moraes.

Saviani, D. (2007). O plano de desenvolvimento da educação: Análise do projeto do MEC. Educação \& Sociedade, 28(100), 1231-1255.

Simielli, L. (2008). Coalizões em educação no Brasil. São Paulo: Fundação Getúlio Vargas.

Todos Pela Educação. (2006a). Compromisso Todos Pela Educação. São Paulo: Todos pela Educação.

Todos Pela Educação. (2006b). Todos Pela Educação. Rumo a 2022. São Paulo: Todos pela Educação.

Todos Pela Educação. (2007a). História, conquista e visão de futuro. São Paulo: Todos pela Educação.

Todos Pela Educação. (2007b). Relatório de Atividades do Todos Pela Educação 2007. São Paulo: Todos pela Educação.

Todos Pela Educação. (2010). De olho nas metas 2010. São Paulo: Todos pela Educação.

Todos Pela Educação. (2012). Todos Pela Educação: 5 anos, 5 metas, 5 bandeiras. São Paulo: Todos pela Educação. 
Todos Pela Educação. (2014). Relatório de Atividades do Todos Pela Educação 2014. São Paulo: Todos pela Educação.

União Europeia. (2013). Cooperación regional por la calidad de la educación en América Latina (Internacional Cooperation and Development). Disponível em: https:// ec.europa.eu/europeaid/node. Acesso em: $30 / 03 / 2017$

\section{STRATEGIES AND BUSINES} ADVOCACY IN THE CURRENT BRAZILIAN EDUCATIONAL POLICY: THE CASE OF THE 'ALL FOR EDUCATION'MOVEMENT

\section{Abstract}

We can observe in the current Brazilian education policy, the influence of entrepreneurial organizations that interweave with the political scenario, among which, the 'Movimento Todos pela Educação' (TPE - All for Education Movement) stands out. We used extensive documentary research and interviews with the main actors of the organization. We aim to introduce this movement and discuss its objectives and main strategies concerning the Brazilian education policy. The TPE Movement acts as a broad coalition, organizing itself in a dense network and acting as a 'Think Tank' on education. This study identifies signs of a new restructuration phase of public space and institutions, where entrepreneurs seek to strengthen the operational capability of governmental and institutional apparatus, assuming the command of this process in the name of the social control demand.
KEY-wORDS: Education Reforms; Education and entrepreneurs; Education policies; Advocacy; Brazil

STRATÉGIES ET PLAIDOYER D'ENTREPRISE DANS LA POLITIQUE ÉDUCATIVE BRÉSILIENNE ACTUELLE : LE CAS DU MOUVEMENT "TOUT POUR L'É D U C A T I O N'

\section{RESUMÉ}

Nous observons l'influence constante des organisations d'entreprise dans la politique éducative brésilienne, ces organisations s'entrelacent avec les groupes politiques, on distingue parmi ces organisations le 'Movimento Todos pela Educação' (Mouvement Tous pour l'Éducation - TPE). Nous avons utilisé une recherche documentaire approfondie et des entretiens avec les acteurs clés de l'organisation. Ici les auteurs ont le but de présenter le TPE, discuter ses objectifs et stratégies principales pour s'insérer dans la politique éducative brésilienne. Le TPE opère comme une large coalition, ce mouvement sorganise sur un réseau dense et agit comme un 'Think Tank' de l'éducation. Cet article identifie signes d'une nouvelle étape de restructuration de l'espace public et de ses institutions. Dans ce stage, les entreprises veut la fortification de la capacité de produire de l'appareil de l'état et l'institutionnelle, en guidant ce procès, au nom de la nécessite du contrôle social.

MoTS-CLÉs: La reforme éducative; L' éducation e les entreprises; Les politiques éducatives ; Advocacy; Brésil

\footnotetext{
${ }^{1}$ Programa de Pós-graduação em Educação, Faculdade de Educação/Unicamp, Brasil ORCID: http://orcid.org/0000-0002-1029-2057

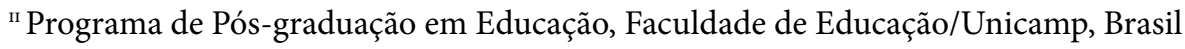




\section{ANEXO 1}

Rede de relações dos sócios fundadores do TPE*

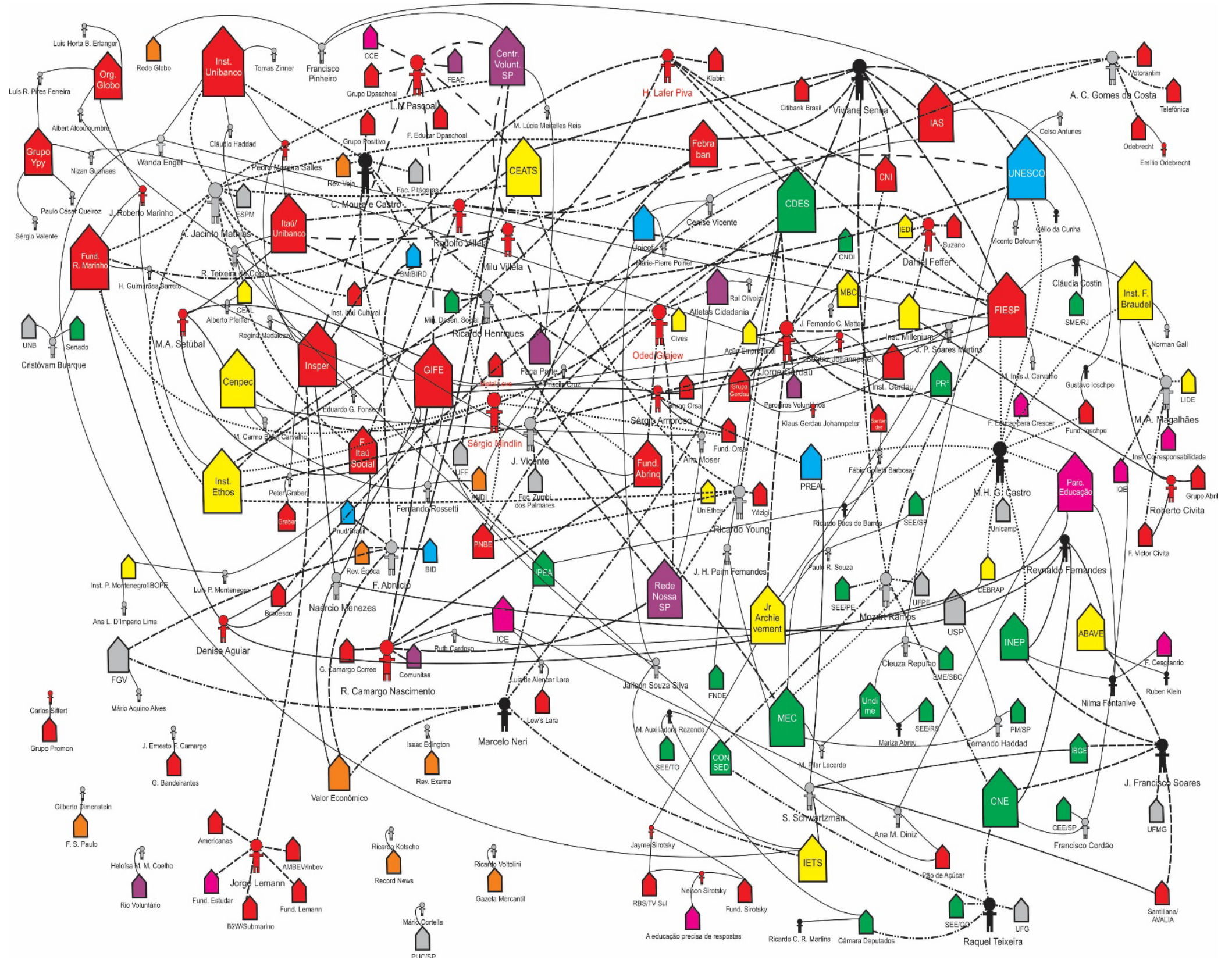

Legenda:

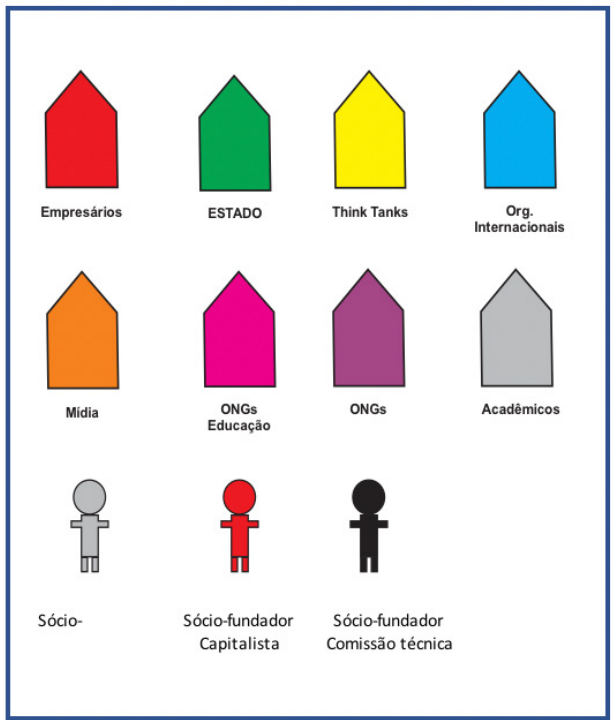

* Dadas as limitações de diversas ordens - como a grande mobilidade ou a impossibilidade em se verificar a intensidade das ligações entre sujeitos e entidades -, o grafo apresentado é meramente ilustrativo da rede de relações do TPE. 